Các chỉ số BTNT theo thời gian ở người bệnh Đái tháo đường typ 2 có đường huyết không ổn định giảm hơn so với người bình thường. SDNN, ASDNN, SDANN tương quan thuận với HbA1c ở nhóm đường huyết cao và tương quan nghịch mức độ vừa với HbA1c ở nhóm hạ đường huyết và tương quan yếu với nồng độ đường huyết.

\section{TÀI LIỆ THAM KHẢO}

1. Guideline ADA 2020. Glycemic Targets: Standards of Medical Care in Diabetes-2020 | Diabetes Care.

2. Huỳnh Văn Minh. Holter Điện Tâm Đồ 24h Trong Bệnh Lý Tim Mạch.

3. Kudat, H.; và cs. Heart Rate Variability in Diabetes Patients. J. Int. Med. Res.2006, 34 (3), 291-296.
4. Vukomanovic, V. và cs. Association between Functional Capacity and Heart Rate Variability in Patients with Uncomplicated Type 2 Diabetes. Blood Press.2019, 28 (3), 184-190.

5. Benichou, T. và cs. Heart Rate Variability in Type 2 Diabetes Mellitus: A Systematic Review and Meta-Analysis. PLOS ONE 2018, 13 (4), e0195166.

6. Victoria L Fisher và cs. Cardiac autonomic neuropathy in patients with diabetes mellitus: current perspectives. Dovepress J. Diabetes, Metabolic Syndrome and Obesity: Targets and Therapy 2017:10 419-434.

7. Chow, E; và cs. Risk of Cardiac Arrhythmias During Hypoglycemia in Patients With Type 2 Diabetes and Cardiovascular Risk. Diabetes 2014, $63(5), 1738-1747$.

\title{
ĐÁNH GIÁ KẾT QUẢ ĐIỀU TRI PHẪU THUÂT XUẤT HUYẾT TIÊU HÓA DO UNG THƯ HANG MÔN VỊ DẠ DÀY XÂM LẤN ĐẦ TỤY, DI, DII TÁ TRÀNG
}

\section{TÓM TẮT}

Xuất huyết tiêu hóa (XHTH) do ung thư hang môn vị da dày là một biến chứng của ung thư da dày. Cho tới nay việc điều trị phẫu thuật (PT) còn gặp nhiều khó khăn do bệnh nhân (BN) thường đến muộn, khối ung thư đã xấm lấn những thành phần xung quanh, DI, DII tá tràng, đâuu tụy, cuống gan... do đó PT trớ thành thách thức lớn giứa PT triệt căn, PT làm sach hay PT tạm thời. Mặt khác, cấu trúc giải phẫu và đặc điểm sinh lý vùng cuống gan, tá tràng, đâu tụy phức tạp nên phâu thuật có tỷ lệ thất bại, tai biến và biến chứng khá cao, khó thực hiện. Bởi vậy chúng tôi tiến hành nghiễn cứu này với mục tiêu: Đánh giá kết quả điều trị phẫu thuật XHTH do ung thư hang môn vị xâm lấn DI, DII tá tràng, đầu tụy. Phương pháp nghiên cứu (NC): Phương pháp mô tả hồi cứu. Đối tượng NC: Bệnh nhân được chẩn đoán XHTH do ung thư hang môn vị dạ dày, được điều trị PT tại khoa ngoại bụng 2, bệnh viện $K$, có tổn thương trong mổ là ung thư hang môn vị xâm lấn đầu tụy và/hoặc DI, DII tá tràng. Đia điểm: Bênh viện $K$ K Trung ương. Thời gian: 1/2019-12/2020. Kết quả nghiên cứu: Có 8 bênh nhân, $100 \%$ là nam, tuổi trung bình: 59,9 tuổi; $6 \dot{2}, 5 \%$ lia phân đen, $37,5 \%$ nôn máu và ía phân đen, $75,0 \%$ khám sớ thây khối u, thiếu máu nhe: $5 / 8(62,5 \%)$, thiếu máu vừa: 3/8.(37,5\%). Nội soi dạ dày(NSDD): Forrest Ib: $1 / 8(12,5 \%)$, Forrest IIc: $7 / 8(87,5 \%), 75 \%$ ung thư hang môn vị, hẹp môn vị (HMV), 25\% ung thư hang môn vị xâm lấn DI, DII. Tổn thương trong mổ: $87,5 \%$ ung thư đã xâm lấn DI,

*Bệnh viện $K$

Chịu trách nhiệm chính: Thái Nguyên Hưng

Email: Thainguyenhung70@gmail.com

Ngày nhận bài: 7.7.2021

Ngày phản biên khoa họ: 3.9.2021

Ngày duyệt bài: 10.9.2021

\section{Thái Nguyên Hưng*}

DII, 12,5\% ung thư xâm lấn đầu tụy, 3/8(37,5\%) ung thư thủng (xâm lấn DI, DII, thủng vào đâu tụy). Xử trí PT: $100 \%$ các trường hợp được cắt $4 / 5 \mathrm{DD}$, đóng mỏm tá tràng mũi rời kiểu con sện (khó khăn), 01 BN đóng mỏm tá tràng kết hợp dẫn lưu ( $\mathrm{DL}$ ) mỏm tá tràng. Không có $B N$ nào tử vong. Biến chứng sau mổ: $1 \mathrm{BN}$ viêm tụy cấp hoại tử, rò miêng nối điều trị nộ khoa. Kết quả GPB: Giai đoạn IB:1(12,5\%), giai đoạn IIIA: $3(37,5 \%)$, giai đoạn IİIB: $3(37,5 \%)$, giai đoạn IIIC:1 (12,5\%). Kết luân: XHTH do ung thư hang môn vị dạ dày xâm lấn DI, DII tá tràng, đầu tuy là ung thư dạ dày đến muộn, có thể đã thủng vào DI DII tá tràng, đâu tự. Đa số tổn thương DI, DII tá tràng và đầu tuy chỉ được phát hiện trong mổ. Xử trí PT khó khăn,có thể đóng mỏm tá tràng mũi rời (kiểu con sên) hoặc dẫn lưu mỏm tá tràng.

\section{SUMMARY \\ TO EVALUATE THE SURGICAL RESULT OF BLEEDING DISTAL GASTRICCANCER INVALIDING DI,DII DUODENUM AND HEAD OF PANCREAS}

Bleeding distal gastric cancer invading DI,DII duodenum and head of pancreas is a complication of distal gastric cancer. The lesions could be combination of pyloric stenosis, perforgation to DI,DII of duodenum. The surgical management needed good technical skills of closing duodenum stump as well as making ist drainage in case of closing stump dundenum dificulty. Study aims: To Evaluate the result of surgical management of bleeding distal gastric cancer that invade DI, DII duodenum and/or head of pancreas. Patient and methode: Retrospective study.All the patients who had bleeding distal gastric cancer invading the head of pancreas and/or DI, DII of Duodenum. Period: 1/201912/2020. Results: 8 patients, $100 \%$ males, mean age 
59,9 ; melena in 62,5\%, hematemesis and melena in $37,5 \%$. Endoscopic results (preoperation) Pyloroantriccancer with stenosis in $75,0 \%$. Pyloroantriccancer invading DI, DII of Duodenum in $25,0 \%$. Lesions (peroperation): $87,5 \%$ tumors invade DI, DII $12,5 \%$ of tumors invade the head of pancreas, $37,5 \%$ of tumors perforated into head of pancreas. Surgical methode: Subtotal gastrectomy with interrupted closure of duodenal stump in $87,5 \%$ (DII lymph node dissection). Subtotal gastrectomy with Duodenal drainage in $12,5 \%$ (DII lymph node dissection). Complication postoperation: 1 patient had pancreatic necrosis and annastomotic leakage that stopped with medical treatment (continous aspiration). There is no death per and post opeeration. Consclusion: We conclude that distal gastric bleeding cancer invading DI,DII Duodenum and head of pancreas are serious lesions that require technical skills and good surgical method of duodenal stump closure as well as duodenal drainage in case of difficulty in its closure.

Keywords: Bleeding gastric cancer,duodenal stump closure.

\section{I. ĐẶT VẤN ĐỀ}

XHTH do ung thư da dày là một cấp cứu thường gặp với tỷ lệ ngày càng cao. Mặc dù đã ứng dụng nhiều phương pháp để chẩn đoán và điêu trị nhưng tỷ lệ tử vong còn khá cao (tỷ lệ này với XHTH cao là 10-11\%). Mặt khác bệnh nhân ung thư hang môn vị dạ dày thường đến muộn khi ung thư đã xâm lấn đâu tụy, DI, DII tá tràng hay cuống gan đặt ra nhiều thách thức cho phẫu thuật viên trong phẫu thuật triệt căn, đặc biệt là những trường hợp XHTH nặng có mạch huyết áp không ổn định hoặc ung thư đã thủng vào đâu tụy, DI, DII tá tràng. Bởi vậy chúng tôi nghiên cứu đề tài này nhằm mục tiêu mô tả những đặc điểm lâm sàng và cận lâm sàng và đánh giá kết quả phẫu thuật bệnh lý XHTH do ung thư hang môn vị dạ dày xâm lấn đâu tụy, DI, DII tá tràng, cuống gan.

\section{II. ĐỐI TƯợNG VÀ PHƯƠNG PHÁP NGHIÊN CỨU}

Đối tượng nghiên cứu: Tất cả những trường hợp XHTH do ung thư hang môn vị dạ dày xâm lấn đâu tụy và/hoặc DI, DII tá tràng (phát hiênn trước và trong mổ) được đưa vào NC theo mấu hồ sơ định sẵn bao gồm: tên, tuổi, giới, triệu chúng lâm sàng, xét nghiệm cận lâm sàng (CLS), siêu âm bụng (SA) chụp cắt lớp vi tính ổ bụng (CLVT), nội soi dạ dày (NSDD), đánh giá tổn thương trong mổ, kết quả mổ, kết quả giải phẫu bệnh (GPB).

Phương pháp nghiên cứu: Nghiên cứu mô tả hồi cứu.

Thời gian: 1/2019-12/2020.

III. KẾT QUẢ NGHIÊN CỨU
Có 8 BN đủ tiêu chuẩn được đưa vào nghiên cứu (NC). Tuổi trung bình của mấu nghiên cứu là 59,9 tuổi. Giới: 100\% BN là nam.

Triệu chứng lâm sàng:

Bảing 1: Triệu chứng lâm sang

\begin{tabular}{|c|c|c|}
\hline Triệu chứng lâm sàng & $\mathbf{n}$ & $\mathbf{0}$ \\
\hline İa phân đen & 5 & 62,5 \\
\hline Nôn máu + ỉa phân đen & 3 & 37,5 \\
\hline Khám sờ thấy u & 6 & 75,0 \\
\hline Không sờ thấy u & 2 & 25,0 \\
\hline Hẹp môn vị (HMV) & 3 & 37,5 \\
\hline Không hẹp môn vị & 5 & 62,5 \\
\hline
\end{tabular}

Xét nghiệm máu: Thiếu máu nhẹ: $5 \mathrm{BN}$ (62,5\%); thiếu máu vừa 3 BN $(37,5 \%)$

Kết quả nội soi dạ dày (NSDD):Theo Forrest: Ib: 1 BN(12,5\%); IIc:7 BN (87,5\%).

Tổn thương ung thư hang môn vị qua NSDD:

Bảng 2: Tổn thương ung thư hang môn vi qua NSDD

\begin{tabular}{|c|c|c|}
\hline Tổn thương & $\mathbf{n}$ & $\mathbf{\%}$ \\
\hline $\begin{array}{c}\text { Ung thư thâm nhiếm hang } \\
\text { môn vị, hẹp }\end{array}$ & 6 & 75,0 \\
\hline $\begin{array}{c}\text { Ung thư thâm nhiếm hang } \\
\text { môn vị tá tràng }\end{array}$ & 2 & 25,0 \\
\hline Tống & $\mathbf{8}$ & $\mathbf{1 0 0 , 0}$ \\
\hline
\end{tabular}

Các trường hợp hẹp môn vi không soi được xuống tá tràng.

Kết quả sinh thiết(ST):

Ung thư biểu mô tuyến(BMT) kém biệt hóa: $5 / 8(62,5 \%)$

Ung thư BMT biệt hóa vừa: 1/8 (12,5\%)

Ung thư BMT biệt hóa cao: 1/8 (12,5\%)

Ung thư biểu mổ tế bào nhẫn:1/8 (12,5\%)

Kết quả chụp cắt lớp vi tính( CLVT)

Bảng 3: Kết quả chụp CLVT

\begin{tabular}{|c|c|c|}
\hline Tổn thương & $\mathbf{n}$ & $\mathbf{\%}$ \\
\hline Dày thành dạ dày < 2cm & 1 & 12,5 \\
\hline Dày thành dạ dày $2-5 \mathrm{~cm}$ & 4 & 50,0 \\
\hline Dày thành dạ dày >5 cm & 2 & 25,0 \\
\hline Không dày thành dạ dày & 1 & 12,5 \\
\hline Có hạch ố bụng & 4 & 50,0 \\
\hline Không có hạch ổ bụng & 4 & 50,0 \\
\hline Có dịch ố bụng & 2 & 25,0 \\
\hline Không có dịch ổ bụng & 6 & 75,0 \\
\hline
\end{tabular}

Tổn thương trong mổ:

Bảng 4: Tổn thương trong mổ

\begin{tabular}{|c|c|}
\hline Tốn thương & $\mathbf{n}(\%)$ \\
\hline $\begin{array}{c}\text { Ung thư hang môn vị xâm lấn } \\
\text { DI+DII }\end{array}$ & $1(12,5 \%)$ \\
\hline $\begin{array}{c}\text { Ung thư hang môn vị thủng vào } \\
\text { đâu tụy, xâm lấn DI-DII *. }\end{array}$ & $2(25 \%)$ \\
\hline Ung thư hang môn vị thủng vào & $1(12,5 \%)$ \\
\hline
\end{tabular}




\begin{tabular}{|c|c|}
\hline đầu tụy * & \\
\hline $\begin{array}{l}\text { Ung thư hang môn vị xâm lấn DI- } \\
\text { DII, cuống gan }\end{array}$ & $4(50 \%)$ \\
\hline Kích thước $(\mathrm{KT})$ ung thư $5-8 \mathrm{~cm}$ & $5(62,5 \%)$ \\
\hline KT ung thư $>8 \mathrm{~cm}$ & $3(37,5 \%)$ \\
\hline
\end{tabular}

Cách thức phẫu thuật (PT): Cắt 4/5 DD triệt căn, vét hạch DII, đóng mỏm tá tràng mũi rời ( kiểu con sển).

Cắt $4 / 5$ dạ dày triêt căn, vét hạch DII - dẫn lưu mỏm tá tràng (không đóng được mỏm tá tràng do ung thư xâm lấn DII sát bóng Vater).

Tỷ lệ tử vong và biến chứng sau mổ: Không có $\mathrm{BN}$ nào tử vong

Biến chứng: $1 \mathrm{BN}$ viêm tụy cấp hoại tử vào động mạch của mạc treo đại tràng phải gây sốc mất máu ngày thứ 6 sau mổ cắt da dày, mổ cấp cứu khâu cầm máu. Xuất hiện rò miệng nối sau mổ lần 2 được đặt sonde qua vết mổ hút rửa liên tục, dẫn lưu mỏm tá tràng ra tốt, BN được nhét rau thai 3 lần sau đó $B N$ hết rò.

Giai đoạn bệnh: Giai đoạn IB:1 BN (12,5\%), giai đoạn IIIA: 3BN (37,5\%); giai đoạn IIIB:3 (37,5\%), giai đoạn IIIC:1 BN (12,5\%).

\section{BÀN LUẬN}

Điều trị phẫu thuật XHTH do ung thư vùng hang môn vị còn gặp rất nhiều khó khăn do $B N$ thường đến viện muộn, thiếu máu và mất máu nhiều trên $\mathrm{BN}$ có khối u lớn nhiều trường hợp đã thủng bít, hẹp môn vị...[5]

Số liệu của chúng tôi cho thây có 3 trường hợp XHTH do ung thư dạ dày đã thủng trong đó $2 \mathrm{BN}$ thủng vào đâu tụy, DI, DII, 01 trường hợp thủng vào đầu tụy.Các trường hợp này vửa XHTH vừa thủng do ung thư hang mồn vị nên chỉ định cắt dạ dày cầm máu và kết hợp xử trí tổn thương thủng. Tuy nhiên việc đóng mỏm tá tràng trong trường hợp ung thư dạ dày xâm lấn DI, DII rất khó khăn vì mỏm tá tràng rất mủn, lại sát bóng vater do vậy có thể gây rò mỏm tá tràng và tắc mật. Trong $8 \mathrm{BN}$ này có 1 trường hợp chúng tôi không đóng được mỏm tá tràng mà phải dẫn lưu mỏm tá tràng do tổn thương hang môn vị lớn (khoảng $10 \mathrm{~cm}$ ) đã thủng vào đầu tụy và DII, sát bỏng Vater. BN này hậu phẫu ổn đinh, DL mỏm tá tràng ra tốt nhưng ngày thứ 6 sau mổ xuất hiện chảy máu trong ổ bụng phải mổ cấp cứu. Mổ ra là viêm tụy cấp hoại tử vào mạch máu mạc treo đại tràng ngang gây chảy máu, mổ khâu cầm máu. Sau mổ lần 2 BN xuất hiện rò miệng nối vị tràng được xử trí luồn sonde qua vết mố hút liên tục. $B N$ này $D L$ mỏm tá tràng ra tốt $(600 \mathrm{ml}-800 \mathrm{ml} / \mathrm{ngày})$ kết hợp hút liên tục sau đó được điều trị rò miệng nối bằng nhét rau thai (3 lần). Lượng dịch qua vết mổ giảm dần và hết sau khoảng 1 tháng. Sau đó chúng tôi rút $\mathrm{DL}$ mỏm tá tràng sau 3 tháng.

Rò miệng nối vị tràng theo Trịnh Hồng Sơn gặp 0,98\% (3/306), có 2 BN tử vong. Đổ Đức Vần và CS gặp $0,8 \%(n=717)$, Phạm Duy Hiển và CS gặp $1,2 \%(n=169)[1]$.

Rò mỏm tá tràng thường gặp khi cắt dạ dày do loét dạ dày tá tràng lành tính đặc biệt là loét sâu ở DI, DII tá tràng. Loét mặt sau thủng, trong lô $\mathrm{BN}$ của chúng tôi có trường hợp trên $\mathrm{DL}$ mỏm tá tràng chủ động, còn lại các BN khác mặc dù tổn thương hang môn vị xâm lấn DI, DII, đóng mỏm tá tràng rất khó khăn nhưng không có $B N$ nào rò mỏm tá tràng. Tỷ lệ rò mỏm tá tràng theo Phạm Duy Hiển và CS khoảng 1-2\% [1].

Chúng tôi nhận thấy rằng các tổn thương vùng DI-DII và đầu tụy xử trí gặp nhiều khó khăn do không có chụp đường mật trong mô trên bệnh nhân XHTH có mạch huyết áp không ổn định nên việc thăm dò tổn thương xâm lấn bóng Vater gặp rất nhiều khó khăn.

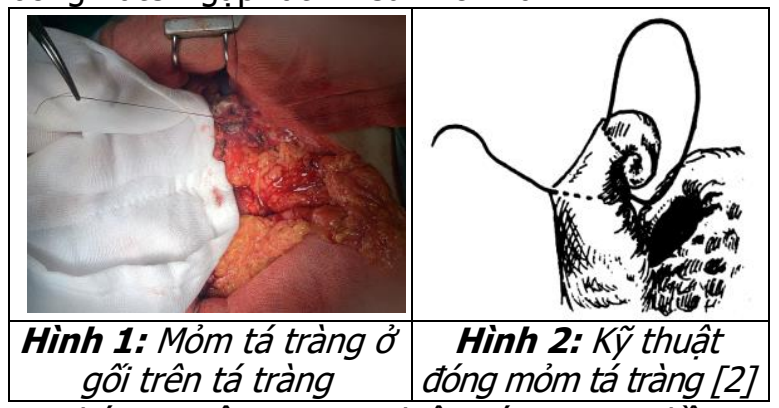

Thái Nguyên Hưng nghiên cứu 28 BN điêuu trị phẫu thuật XHTH tại BV K [3] cho thây có 3 trường hợp XHTH do Kissing ulcer ở DI, DII tá tràng (loét 2 mặt) gây sốc mất máu được mổ cấp cứu. Hai trong ba BN này được PT mở DII khâu cầm máu, nối vị tràng. Trường hợp còn lại sốc mất máu nặng, HA chỉ 50-60 mmhg, mạch $140 \mathrm{l} /$ phút, tổn thương loét 2 mặt tá tràng trong đó mặt sau loét $2,5-3 \mathrm{~cm}$ đã thủng vào tụy và động mạch (ĐM) vị tá tràng chảy máu thành tia (đã thất bại qua can thiệp nội soi, chuyển thẳng phòng mổ cấp cứu). BN được cắt túi mật, dùng stylet qua ống cổ túi mật xuống thây loét mặt sau có kích thước lớn thủng vào ĐM vị tá tràng và ăn vào đường mật (mặt trước loét $1 \mathrm{~cm}$ tá tràng, không chảy máu). BN này được PT cắt $2 / 3$ dạ dày lấy tổn thương loét 2 mặt tá tràng hoại tử, dẫn lưu (DL) mỏm tá tràng, khâu và $\mathrm{DL}$ đường mật qua Kehr $10 \mathrm{Fr}$, sau mổ BN không chảy máu, rò mật giảm dân, DL mỏm tá tràng ra tốt. 
Số liêu 28 BN trên còn cho thấy có $5 / 28$ trường hợp XHTH do ung thư hang môn vị dạ dày xâm lấn cuống gan, DI và gối trên được cắt dạ dày bán phần và đóng mỏm tá tràng mũi rời (mỏm tá tràng sâu, mủn, khó đóng) [3]

Như vậy khi tổn thương ung thư dạ dày vùng hang môn vị xâm lấn DI,DII,đầu tụy hoặc những tổn thương loét thủng hoại tử chảy máu việc PT triêt để lấy tổn thương, cầm máu và điều trị triêt căn, dẫn lưu mỏm tá tràng là kỹ thuật vừa làm giảm nguy cơ rò mỏm tá tràng, đảm bảo an toàn cho miệng nối đồng thời tránh tổn thương bóng Vater. Chúng tôi thường dẫn lưu trực tiếp qua mỏm (không dẫn lưu qua thành bên tá tràng).

Mặt khác kỹ thuật đóng mỏm tá tràng cũng mang tính quyết định cho PT triệt căn, lấy triệt để tổn thương $(\mathrm{XHTH})$ : Toàn bồ $8 \mathrm{BN}$ này đều được đóng mỏm tá tràng mũi rởi kiểu con sên, đây là kỹ thuật được áp dụng nhiều khi mỏm tá tràng sâu ở gối trên hoặc DII gặp trong loét mặt sau tá tràng, loét lớn hoại tử vào $Đ M$ vị tá tràng và /hoặc đường mật, làm biến đổi giải phẫu vùng DII dẫn tới đóng mỏm tá tràng cũng như nhận định tổn thương xâm lấn bóng Vater và đường mật rất khó khăn.

Đóng mỏm tá tràng với tổn thương sâu như vậy rất cần chụp đường mật trong mổ.ở nhiều nước chụp đường mật trong mổ là kỹ thuật thường quy đối với cắt túi mật nội soi, tuy nhiền ở nước ta, kỹ thuật chụp đường mật trong mổ chưa được ứng dung nhiều. Để phát hiện và/hoắc tránh làm tổn thương đường mật chúng tôi cắt túi mật sau đó qua ống cổ túi mật dùng stylet hoặc sonh 8-10 FR xuống phần thấp ống mật chủ và tá tràng để thăm dò đường mật [6]. Số liệu cho thấy từ T8/1998-8/1999 tại BV Chợ Rẫy: 170 bênh nhân thủng do loét da dày tá tràng, $12 \mathrm{BN}$ thủng do ung thư dạ dày (chiếm 7\%) [7].

Thống kê của Nguyễn Võ Vĩnh Lộc cho thấy trong 50 bn thủng da dày do ung thư da dày được PT: Không có BN nào được PT triệt căn: 17 Bn được cắt u làm sạch, 33 BN được khâu lỗ thủng hay PT Newmann. Biến chứng 14\% (7/50) và tử vong $12 \%(6 / 50)$ [4].

Như vậy cả $8 \mathrm{BN}$ trong $\mathrm{NC}$ này đều được cắt dạ dày triệt căn, nạo vét hạch DII. Kết quả PT cho thây không có trường hợp nào rò mỏm tá tràng.Có $1 \mathrm{BN}$ được $\mathrm{DL}$ mỏm tá tràng chủ động.

Kết quả GPB cho thấy có tới 7/8 BN giai đoạn III (IIIa:3, IIIb:3, IIIc:1), 1 BN giai đoạn Ib.

Trường hợp này (GFB: GĐ $1 b)$ XHTH và hep môn vị do khối ung thư hang môn vi xâm lấn môn vị, gối trên tá tràng. Chụp CLVT: khối u KT 86-22mm hang môn vị gây hẹp, tổn thương trong mổ là khối u hang môn vị xâm lấn cuống gan và gối trên tuy nhiên kết quả GPB u chỉ xâm lấn tới lớp cơ (tế bào nhẫn).

Đánh giá trong mổ cũng cho thấy có tới $62,5 \%$ các BN có khối ung thư $5-8 \mathrm{~cm}, 3$ BN có khối u $>8 \mathrm{~cm}$.

Đối chiếu NSDD với phẫu thuâtt cũng cho thấy chỉ có 2 trường hợp NSDD phát hiện có tổn thương tá tràng trước mổ. Sáu BN còn lại khối ung thư đã gây hẹp môn vị (HMV), bởi vậy tổn thương DI,DII chỉ được phát hiện trong mố.

Trên lâm sàng có $3 \mathrm{BN}$ có triệu chứng hẹp môn vị rõ (HMV) tuy nhiên NSDD có 6 BN hẹp môn vị cho thây những bệnh nhân HMV này là hẹp không hoàn toàn nên lâm sàng không biểu hiện rõ.

Trần Thiện Trung và CS từ 1/2001- tháng $5 / 2005$ có 35 trường hợp HMV trong đó 23 BN hẹp môn vị do ung thư dạ dày, $12 \mathrm{BN}$ do loét. Các $\mathrm{BN}$ ung thư dạ dày có $12 \mathrm{BN}$ được cắt da dày bán phần dưới, nạo hạch DII; có $6 \mathrm{BN}$ cắt dạ dày làm sạch; $4 \mathrm{BN}$ được nối vị tràng, $1 \mathrm{BN}$ được mở thồng hỗng tràng [7].

Đặc điểm lâm sàng của những $\mathrm{BN}$ trong NC này cho thấy biểu hiện của XHTH chủ yếu là ỉa phân đen số lượng ít và vừa, NSDD có $1 \mathrm{BN}$ có Forrest Ib, 7/8 bệnh nhân NSDD có máu đen trong dạ dày. Như vậy XHTH do ung thư hang môn vị thường biểu hiện nhẹ,chảy máu rỉ rả không chảy dữ dội như XHTH do loét dạ dày tá tràng, đặc biệt là ổ loét sâu mặt sau tá tràng thủng vào ĐM vị tá tràng [3], [6].

\section{KẾT LUÂ̂N}

XHTH do ung thư hang môn vị dạ dày xâm lấn $\mathrm{DI}, \mathrm{DII}$, đầu tụy thường là XHTH nhe và vừa.

Tổn thương thường phối hợp với thủng bít vào đầu tụy, $\mathrm{DI}$, DII tá tràng $(3 / 8 \mathrm{BN})$, gây hẹp môn vị $(6 / 8 \mathrm{BN})$. Các tổn thương DI, DII ít được phát hiện trước mổ do hẹp môn vị nên NSDD không xuống được tá tràng.

Các trường hợp ung thư hang môn vị xâm lấn DI, DII thủng vào đâuu tụy và/hoặc xâm lấn cuống gan kết hợp XHTH có mỏm tá tràng mủn và sâu tới gối trên thậm chí tới DII nên đóng mỏm tá tràng khó khăn.

Đóng mỏm tá tràng mũi rời (kiểu con sên): Là phương pháp xử trí mỏm tá tràng có kết quả tốt, có thể dânn lưu mỏm tá tràng khi tổn thương sâu gần bóng Vater, khó hoặc không thăm dò được đường mật [3].

\section{TÀI LIỆU THAM KHẢO}

1. Phạm Duy Hiển (2007), Ung thư dạ dày, Nhà 
xuất bản $Y$ hoc.

2. Vương Hùng (1997), Kỹ thuật ngoại khoa, Nhà xuất bản $Y$ hoc

3. Thái Nguyến Hưng (2020): Đánh giá kết quả điều tri phâu thuât xuất huyết tiêu hóa cao, Đề tài cơ sở BV K.

4. Nguyê̂n Võ Vĩnh Lộc(2013): Đặc điểm lâm sàng,cận lâm sàng và kết quả sớm điều trị thủng dạ dày do ung thư', Luận văn tốt nghiệp bác sỹ nội trú, Đại học Y Dược TP Hồ Chí Minh.
5. Thái Nguyên Hưng và Bùi Thanh Thiện (2021), "Đánh giá kết quả điều trị phẫu thuật xuất huyết tiêu hóa cao do ung thư hang môn vị da dày.", Tạp chí Y học Việt Nam. 504(2).

6. Thái Nguyên Hựng và Trịnh Vằn Tuấn (2013), "Điêuu trị phẫu thuật chảy máu đường mật do sỏi có sử dụng nội soi đường mật bằng ống soi mềm", Tap chí nghiên cứu $Y$ hoc. 83்(3).

7. Trân Thiện Trung (2014), Ủng thư dạ dày bệnh sinh, chẩn đoán, điêu trị, NXB Y học.

\title{
ĐÁNH GIÁ HIỄU QUẢ CỦA PHƯƠNG PHÁP AN THẦN DO BÊNNH NHÂN TỰ ĐIỀU KHIỂN BẰNG PROPOFOL ĐỂ CHỌC HÚT NOÃN THỤ TINH TRONG ỐNG NGHIỆM
}

\author{
Nguyễn Hoàng Định ${ }^{1}$, Nguyễn Duy Ánh ${ }^{2}$, Nguyễn Đức Lam $^{3}$
}

\section{TÓM TẮT}

Muc tiêu: Đánh giá hiệu quả của phương pháp an thần do bệnh nhân tự kiểm soát bằng propofol (PCS) để chọc hút noãn thụ tinh trong ống nghiệm. Phương pháp: Tiến cứu, thử nghiệm lâm sàng ngẫu nhiên có so sánh, 60 bệnh nhân chọc hút noãn được phân bổ ngẫu nhiên thành 2 nhóm. Nhóm 1 (nhóm PCS, $\mathrm{n}_{1}=$ 30) sử dung phương pháp an thần do bênh nhân tự điều khiển (thuốc Propfol 1\%, mối lần bệnh nhân bấm máy sẽ bơm vào $20 \mathrm{mg}$, không cài thời gian trơ. Nhóm 2 (nhóm GM, $\mathrm{n}_{2}=30$ ) là nhóm gây mê tĩnh mạch thông thường (thuốc Propofol $1 \%$ liều $2 \mathrm{mg} / \mathrm{kg}$ tî̃nh mạch ngắt quãng do người gây mê kiểm soát). Bệnh nhân của 2 nhóm đều được sử dụng $0,05 \mathrm{mg} 50$ mcg fentanyl tiêm tĩnh mạch và gây tê cạnh cố tử cung bằng $100 \mathrm{mg}$ lidocain $1 \%$. Chúng tôi đánh giá mức độ an thân $(\mathrm{OAA} / \mathrm{S})$, tổng liều propofol, thời gian hồi tỉnh và xuất viện, tỉ lệ cử động của bệnh nhân khi làm thủ thuât, mức độ hài lòng của bênh nhân và phẫu thuât viên. Kết quả: Nhóm PCS mức độ an thân trung bình từ 3,87 đên 4,2 điểm trong khi nhóm GM có mức đô an thân từ 1,6 đến 2,1 điểm (do lượng propofol tiêu thu ở nhóm PCS là $52,7 \pm 11,1 \mathrm{mg}$ thấp hơn so với nhóm GM $(151,7 \pm 18,9 \mathrm{mg})$, thời gian hồi tỉnh và thời gian xuất viên của nhóm PCS $(1,7 \pm 0,5$ và $56,6 \pm$ $15,4)$ cũng thấp hơn so với nhóm $\mathrm{GM}(6,9 \pm 1,9$ và $86,5 \pm 25,4)$ với $p<0,05$. Tỉ lệ bênh nhân cử động trong khi làm thủ thuật, mức độ hài lòng của phẫu thuật viên và của bệnh nhận của 2 nhóm không có sự khác biệt. Kết luận: Phương pháp an thần do bệnh nhân tự điều khiển (PCS) bằng Propofol, phối hợp với gây tê cạnh cổ tử cung bằng lidocain trong chọc hút noãn có hiệu quả vô cảm tốt, giúp bênh nhân giảm tình trạng an thần sâu, giảm lượng thuốc mê tiêu thụ,

${ }^{1}$ Bệnh viện $A$ Thái Nguyên

${ }^{2}$ Bềnh viện Phù sản HN

${ }^{3}$ Dai hoc Y Hà Nôi

Chịu trách nhiệm chính: Nguyễn Hoàng Định

Email: Hoangdinhgmhs@gmail.com

Ngày nhân bài: 8.7.2021

Ngày phản biên khoa hoc: 3.9.2021

Ngày duyệt bài: 10.9.2021 giảm thời gian hồi tỉnh và thời gian xuất viện so với nhóm gây mê tĩnh mạch thông thường.

Tư khóa: An thần tự kiểm soát, gây tê Paracervical block, chọc hút noãn, nhu câuu propofol, điểm $O A A / S$ ).

\section{SUMMARY \\ PATIENT CONTROLLED SEDATION BY PROPOFOL FOR OOCYTE RETRIEVAL PROCEDURE}

Objectives: Evaluation of the effectiveness of patient-controlled sedation with propofol (PCS) for in vitro fertilization. Methods: Prospective, randomized, comparative clinical trial, 60 patients with oocyte retrieval were randomly assigned to 2 groups. Group 1 (PCS group, $\mathrm{n} 1=30$ ) used patient-controlled sedation (Propfol 1\% drug, each time the patient presses the machine will inject $20 \mathrm{mg}$, no refractory time set Group 2 (GM group), $\mathrm{n} 2=30$ ) was the usual intravenous anesthesia group (Propofol $1 \%$ dose $2 \mathrm{mg} / \mathrm{kg}$ intravenous intermittent controlled by the anesthesiologist). Patients in both groups received $0.05 \mathrm{mg} 50 \mathrm{mcg}$ fentanyl. intravenous injection and paracervical anesthesia with $100 \mathrm{mg}$ lidocaine $1 \%$.We assessed the degree of sedation (OAA/S), total dose of propofol, time to recovery and discharge, and the patient's movement rate during procedure, patient and surgeon satisfaction. Results: The PCS group had an average sedation level of 3.87 to 4.2 points while the GM group had a sedation level of 1.6 to 2.1 points (due to the amount of propofol consumed in the PCS group was $52.7 \pm 11$ points). $1 \mathrm{mg}$ lower than GM group (151.7 $\pm 18.9 \mathrm{mg})$, recovery time and hospital discharge time of PCS group (1.7 \pm 0.5 and $56.6 \pm 15.4)$ as well. lower than that of the GM group $(6.9 \pm 1.9$ and $86.5 \pm 25.4$ ) with $p<0.05$. The percentage of patients moving during the procedure, the surgeon's satisfaction level and of patients of the 2 groups there was no difference. Conclusion: Patient-controlled sedation (PCS) with Propofol, combined with paracervical anesthesia with lidocaine in oocyte retrieval has good analgesia, helps patients reduce deep sedation, reduce anesthetic consumption, 